\title{
Engaged scholarship and public policy decision-making: a scoping review
}

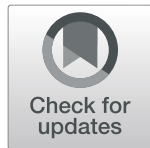

Jessie-Lee D. Mclsaac ${ }^{1,2^{*}}$ (D) and Barbara L. Riley ${ }^{3}$

\begin{abstract}
Background: Engaged scholarship includes the coproduction and use of research by partnerships that blend research, policy and/or practice perspectives. This way of doing research attempts to bridge-the-gap between knowledge and its application. Recent reviews have described practices that support engagement and involve the community in research and patients in healthcare but there is less known about how to engage individuals working to inform public policy.

Aims and objectives: The purpose of this research was to articulate the actions and context that support the coproduction and use of research to inform public policy decisions. The study focuses on partnerships between researchers and stakeholders working in public policy across different levels and sectors of government.

Methods: A scoping review methodology was used. Relevant articles were identified from six electronic bibliographic databases of peer-reviewed literature.

Findings: A total of 9904 articles were screened and 375 full-text articles were assessed for eligibility. The included 11 studies were from research partnerships internationally and described actions and contextual factors contributing to the coproduction and use of research to inform public policy. Key actions included facilitating frequent interactions with public policy stakeholders, joint planning for research, and collaboration to execute data collection and analysis. Contextual factors included clarity in responsibilities, prior relationships, and mutual respect for partner priorities and perspectives.
\end{abstract}

Conclusions: Key actions and contextual factors were identified in this review and warrant further study to strengthen research-policy partnerships and their outcomes.

Keywords: Engaged scholarship, research partnerships, collaboration, public policy

\section{Background}

Engaged scholarship (ES) offers a collaborative approach to research where academicians and non-academicians (e.g. community, policy-makers and other partners) engage in the coproduction and use of knowledge. This way of doing research attempts to bridge the gap

\footnotetext{
* Correspondence: jessie-lee.mcisaac@msvu.ca

${ }^{1}$ Faculty of Education and Department of Child and Youth Study, Mount Saint Vincent University, 166 Bedford Highway, Halifax, Nova Scotia B3M 2J6, Canada

${ }^{2}$ Healthy Populations Institute, Dalhousie University, Halifax, Nova Scotia B3H 4R2, Canada

Full list of author information is available at the end of the article
}

between knowledge and action by blending the perspectives of those who produce knowledge and those who use knowledge as part of the research process [1]. Forms of ES have emerged across university institutions to affirm the commitment of academia to the scholarship of engagement and address complex population and social issues [2-5]. The characterisation and experiences of ES have focused on research, instruction, service and commercialisation and academic experiences across disciplines of health research, social science, engineering, computer science, information technology and business $[2,4-7]$. As a result of the diversity, ES experience and

C C The Author(s). 2020 Open Access This article is licensed under a Creative Commons Attribution 4.0 International License, which permits use, sharing, adaptation, distribution and reproduction in any medium or format, as long as you give appropriate credit to the original author(s) and the source, provide a link to the Creative Commons licence, and indicate if changes were made. The images or other third party material in this article are included in the article's Creative Commons licence, unless indicated otherwise in a credit line to the material. If material is not included in the article's Creative Commons licence and your intended use is not permitted by statutory regulation or exceeds the permitted use, you will need to obtain permission directly from the copyright holder. To view a copy of this licence, visit http://creativecommons.org/licenses/by/4.0/. The Creative Commons Public Domain Dedication waiver (http://creativecommons.org/publicdomain/zero/1.0/) applies to the data made available in this article, unless otherwise stated in a credit line to the data. 
involvement is variable and shaped by discipline, language, institutional culture, individual roles and understandings [3].

Within the domain of ES for research, the focus is on discovery and inquiry in collaboration with a broad set of community partners that are affected by the issues (e.g. community members, patients, professionals, organisations) and/or by decision-makers (e.g. policy-makers, leaders, managers) who may apply research findings $[4$, 8]. With roots in social sciences, ES emphasises multidirectional learning where different expertise is valued and shared to inform better quality and more relevant research [9]. This is distinctly different from a traditional biomedical knowledge transfer paradigm, where researchers are responsible for doing research and communicating the results to end users [9]. Other terms have been used to describe more recent efforts to engage stakeholders in the co-development of research (e.g. integrated knowledge translation, knowledge mobilisation, dissemination and implementation) and each has its own paradigmatic influences and underpinnings [10]. Biomedical roots in health may limit the extent to which traditions from the social sciences and humanities, like ES, are used to understand and improve research partnerships.

Recent reviews involving ES have explored the roles and implications of community partners in research. These reviews demonstrate variability in practices that facilitate engagement and influence community mobilisation and empowerment as a result of the practice of ES, including trust, linkages, training, resources, institutional processes and sustainability $[8,11-15]$. Studies have also highlighted factors influencing the use of research by policy decision-makers such as the perceptions of evidence, culture and competing influences, and practical constraints $[16,17]$. In population health research, engaging stakeholders working in public policy in research is particularly important to ensure that evidence is produced in a timely manner to influence policy decisions $[18,19]$. ES provides an opportunity to bring together explicit or codified knowledge that is typically represented in scientific literature, with tacit or experiential knowledge that is based on professional expertise and involvement with local communities [20], which can be important in the process of programme planning and decision-making [21]. However, little is known about how those working in public policy, such as government decision-makers and staff, should be engaged in research to bridge the research-to-policy gap. This includes conditions and actions of ES partnerships to optimise public policy and is the focus of the present study.

An extensive and diverse literature addresses questions about research-policy partnerships, particularly in relation to factors that facilitate the use or uptake of research knowledge [22, 23]. Yet, it is unclear what conditions and actions of ES partnerships best support the desired public policy outcomes [24]. Scoping reviews offer a review method to summarise the extent and range of literature on a given topic and to identify gaps in the literature [25]. The purpose of this research was to conduct a scoping review to articulate the actions and context that support the coproduction and use of research knowledge to inform public policy decisions. It was expected that this review would identify strategies for stakeholders working in ES partnerships to enhance their collaborative research efforts and ascertain key areas that require future investigation.

\section{Methods}

The review was guided by the scoping review methodological framework by Arksey and O'Malley [25] and by further recommendations by Levac et al. [26]. The review followed five key steps, including (1) identifying the research question; (2) identifying relevant studies; (3) study selection; (4) charting the data; and (5) collating, summarising and reporting the results.

The contextual sensitivity of a realist lens was used to inform the research question to identify what ES actions work for whom, in what circumstances, in what way and how [27]. We used the word 'action' rather than 'mechanism', which is traditionally used in realist approaches as the review is not about theory-building related to underlying (invisible) mechanisms [28]. We adapted Denyer and Tranfield's approach to developing a wellformulated question for use in a social science or organisational context, which is also informed by a realist approach and uses the CIAO acronym (context, intervention, actions and outcomes) [29]. Our final research questions were - Under what conditions does ES influence the coproduction and use of research to inform public policy? What are the actions that contribute to sustained ES partnerships between researchers and government stakeholders working in public policy? For the purpose of our review, we defined public policy as a government action or inaction that includes formally approved and implemented goals and regulations, practices and programmes [30]. This research question informed the inclusion and exclusion criteria, which were refined iteratively throughout the search process.

The research question informed search concepts to identify relevant studies, with searches performed using the terms 'Policy Makers' AND 'Partnership' AND 'Research'. The team identified example articles within the target subject area. A search strategy was then developed for use in Ovid MEDLINE and tested for retrieval of the target articles. Once finalised, the search strategy was translated to five other databases (Ovid MEDLINE, Embase, Web of Science, ABI/INFORM Global, PAIS 
Index, ERIC). Additional file 1 provides a summary of the search translation for all databases, which includes the literature up until May 2017. Following deduplication of identified articles, an iterative process was used for study screening. Two reviewers (KM/BB and JLM) independently reviewed titles and abstracts, followed by the full articles within the Covidence platform. Reviewers met to discuss discrepancies and refine the inclusion/exclusion criteria (Table 1) as needed [26]. For example, as studies were screened, it became clear that it would be important to focus the screening on collaborations that were enduring to ensure they reflected the intent of a ES partnership, rather than isolated meetings without a clear long-term collaborative purpose.

Data from the final articles were charted to extract information according to a priori characteristics, including title, authors, year, journal, country, public policy issues, type of ES partnership described, methods used to describe or evaluate, stakeholders (research, public policy, other), initiator, funding, duration, actions (including duration, frequency, timing), contextual factors (barriers and facilitators), and public policy outcomes. From the extracted data, we used a thematic analysis approach [31] to code data from the included study and identify themes that related to the key conditions and actions to summarise and report the results.

\section{Results}

A total of 9904 articles were screened (Table 2). Of these, 375 full-text articles were assessed for eligibility (see Additional file 2 for PRISMA flowchart).

Articles were excluded during full-text screening if they did not provide details on the actions contributing to their ES process, if the partnership was not between researchers and public policy decision-makers, and if the partnership was not an explicit and enduring research collaboration aiming to inform public policy. For example, some studies were excluded as they were a project without a long-term collaboration or because they focused on participatory policy-making. A final 29 articles were initially included but 18 of these were excluded from further analysis as they were deemed to be structured as a 'research network' with a shared domain of interest and collective outcomes rather than an explicit 'research partnership' that was focused on carrying out specific project activities within a scope of agreed-upon outcomes. The characteristics of the final 11 studies are described in Table 3.

$N R$ none reported, NSW New South Wales

The included studies were from research partnerships in various countries, including Australia $(n=3)$, Canada

Table 1 Inclusion and exclusion criteria for scoping review

\begin{tabular}{lll}
\hline & Inclusion & Exclusion \\
\hline General criteria & Publication time scan (2000-2017); English & Publication time scan (before 2000); not \\
& language; any study type and design & English language \\
& (e.g. descriptive, experimental, qualitative, &
\end{tabular}

Context

\section{Intervention}

(in this study meaning the engaged scholarship partnership) quantitative)

Includes researchers and individuals working in public policy in any level of government (local/ municipal, provincial/state, federal/national) across low-, middle- and high-income countries and descriptions of their environments (socio-cultural, political, economic); may also include other stakeholders (e.g. community, providers/ practitioners, patients/public)

Description of experiences working together toward the same end goal; focused on collaborative coproduction and use of knowledge (e.g. involvement in teams, developing research/policy questions, designing and conducting methods, disseminating results); enduring collaboration that goes beyond one project/meeting

\section{Actions}

Clear and concrete examples of processes/ steps that outline what was done to engage and support collaborations
Does not involve researchers or individuals working in government (e.g. community, organisational, administrative or clinical); no description of environments

Researchers working independent of decisionmakers and vice versa; only translating information to public policy decision-makers, focusing only on uptake of evidence or policy relevance; a network without an enduring mutual purpose; an isolated meeting or project without a long-term collaboration; focus on participatory policy-making rather than on using research to inform policy; focus on a network without information about the specific use of research to inform policy-making

Not a direct account of an experience of engaged scholarship (no or vague details on the process of how it was implemented such as a commentary or descriptive paper on the topic of engaged scholarship) 
Table 2 Search results from all six databases

\begin{tabular}{llll}
\hline Database & Interface & Dates & Results \\
\hline MEDLINE & Ovid & $2000-$ May 2017 & 2985 \\
Embase & Elsevier & $2000-$ May 2017 & 4722 \\
Web of Science Core Collection & Thomson Reuters & $2000-$ May 2017 & 4320 \\
ERIC & ProQuest & $2000-$ May 2017 & 796 \\
PAIS Index & ProQuest & $2000-$ May 2017 & 251 \\
ABI/INFORM Global & ProQuest & $2000-$ May 2017 & 1121 \\
Total & & & 14,195 \\
Duplicates removed & & & 4291 \\
De-duplicated total (total screened at title/abstract level) & & 9904 \\
\hline
\end{tabular}

$(n=1)$, Fiji $(n=1)$, Germany $(n=1)$, Malaysia $(n=1)$, Sweden $(n=1)$, Tanzania $(n=1)$ and the United States $(n=1)$. Another study included three case studies from African countries, including Kenya, Malawi and Nigeria. None of the included studies explicitly used the term 'engaged scholarship' but were deemed to fit the inclusion criteria for an ES partnership. Various terms were used to describe the partnerships, including action research, alliance, research or academic policy/practice and collective research. Various public policy partners were engaged in research, including those from national, state/provincial and local governments or authorities. Seven studies also engaged other stakeholders such as those from non-government or community organisations, research councils and practitioners. Six included studies were descriptive case studies, without evaluation methods used to systematically collect information on the partnership process or outcomes. Four studies used process evaluation methods to collect information on the partnership, including participant observations, surveys, process diaries, reflective dialogues and meeting notes. One study used a framework to analyse the characteristics of case studies using a framework for research-policy linkages.

Various actions and contextual factors were identified in the included studies as contributing to ES partnerships. With respect to actions, the importance of frequent interactions with public policy stakeholders and co-planning and executing research was discussed as being important in all partnerships. Common methods for interactions included regular email communications, inperson meetings or teleconferences. One study also described weekly visits to government offices which allowed for ongoing and face-to-face discussion with policy actors [38]. Several partnerships held capacitybuilding for stakeholders such as training for data analysis [33], conferences with stakeholders [34] and a national dissemination workshop to share findings of the research [41]. Steering groups, coordinating or management committees and working groups were discussed in several studies as facilitating partnership development [34-36]. Bates et al. [36] further developed a governance structure with members responsible for administrative and operational activities of partnerships and a communication plan. Several studies also discussed appointing team leaders/champions [34, 36-38, 42] or expert/technical personnel from stakeholder groups $[32,36]$ to support partnered research. Communication planning and priority-setting were other reported actions within the included studies [37, 39].

Clarity in responsibilities and respect for partner priorities were key contextual factors that influenced the partnerships in the included studies [33-36, 38]. One study discussed the lack of clarity of their action research methodology, which required more meetings to guide the management team [37]. Tran et al. [41] commented on the differences in perspectives that may create challenges for collaboration, whereas other studies discussed the importance of flexibility in partnerships to allow for acknowledgement and appreciation of cultural differences among stakeholders [35, 38]. Prior experience or relationships among stakeholders and credibility of the researcher were reported to also facilitate partnership development [34, 38]. Contextual limitations related to timing or readiness of stakeholders and continuity of policy actors was also discussed in one study [39].

\section{Discussion}

This study used a scoping review methodology to articulate the actions and context that support the coproduction and use of research knowledge to inform public policy decisions. The purpose was to identify strategies for researchers and policy stakeholders working in ES partnerships to enhance their collaborative research efforts and ascertain key areas that require future investigation. We intentionally used the term 'ES' to connect it with an engagement paradigm, compared to a knowledge transfer paradigm, with its biomedical roots and tendency to focus on communication and dissemination by researchers [9]. In contrast, ES focuses on 


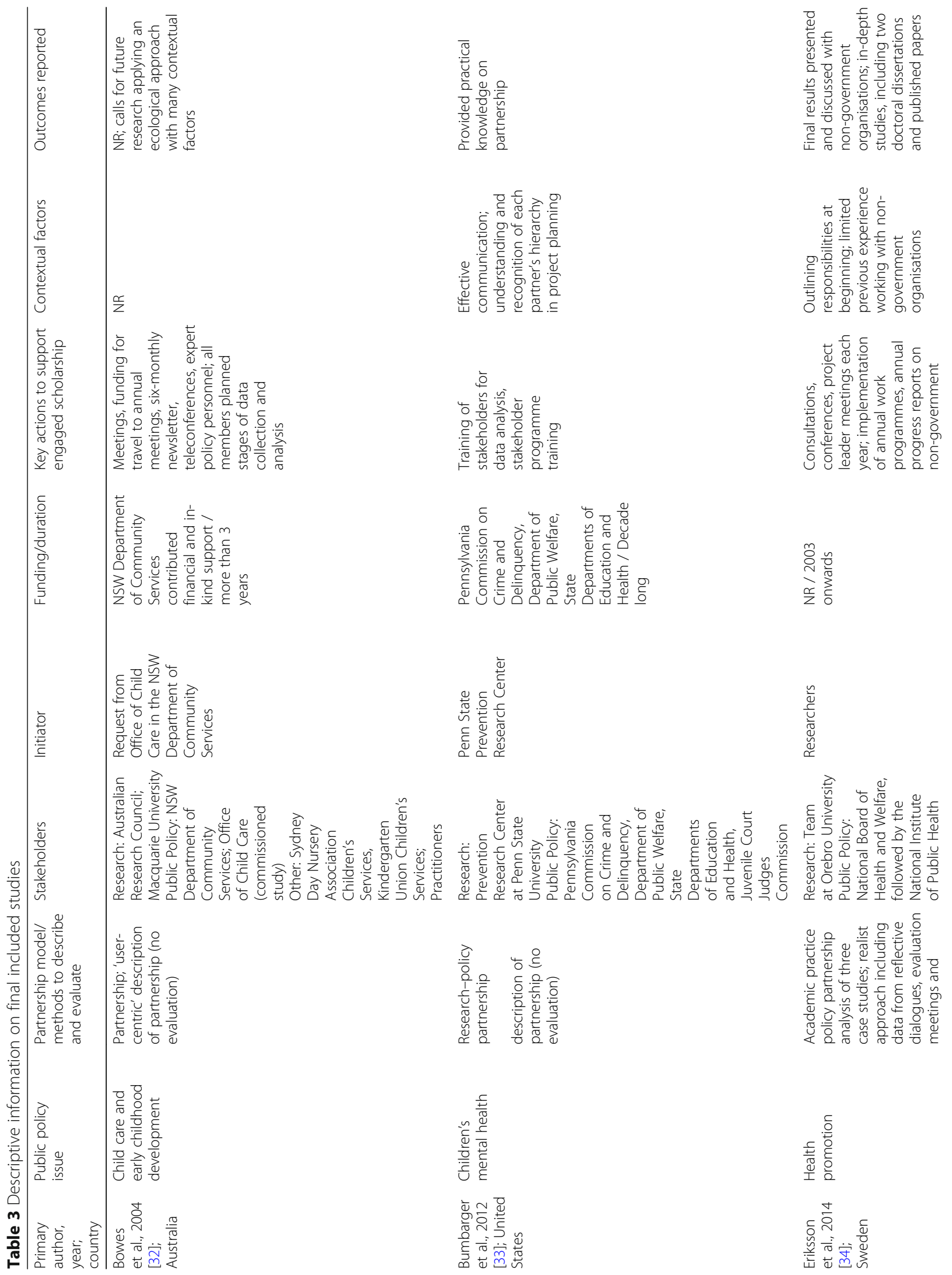




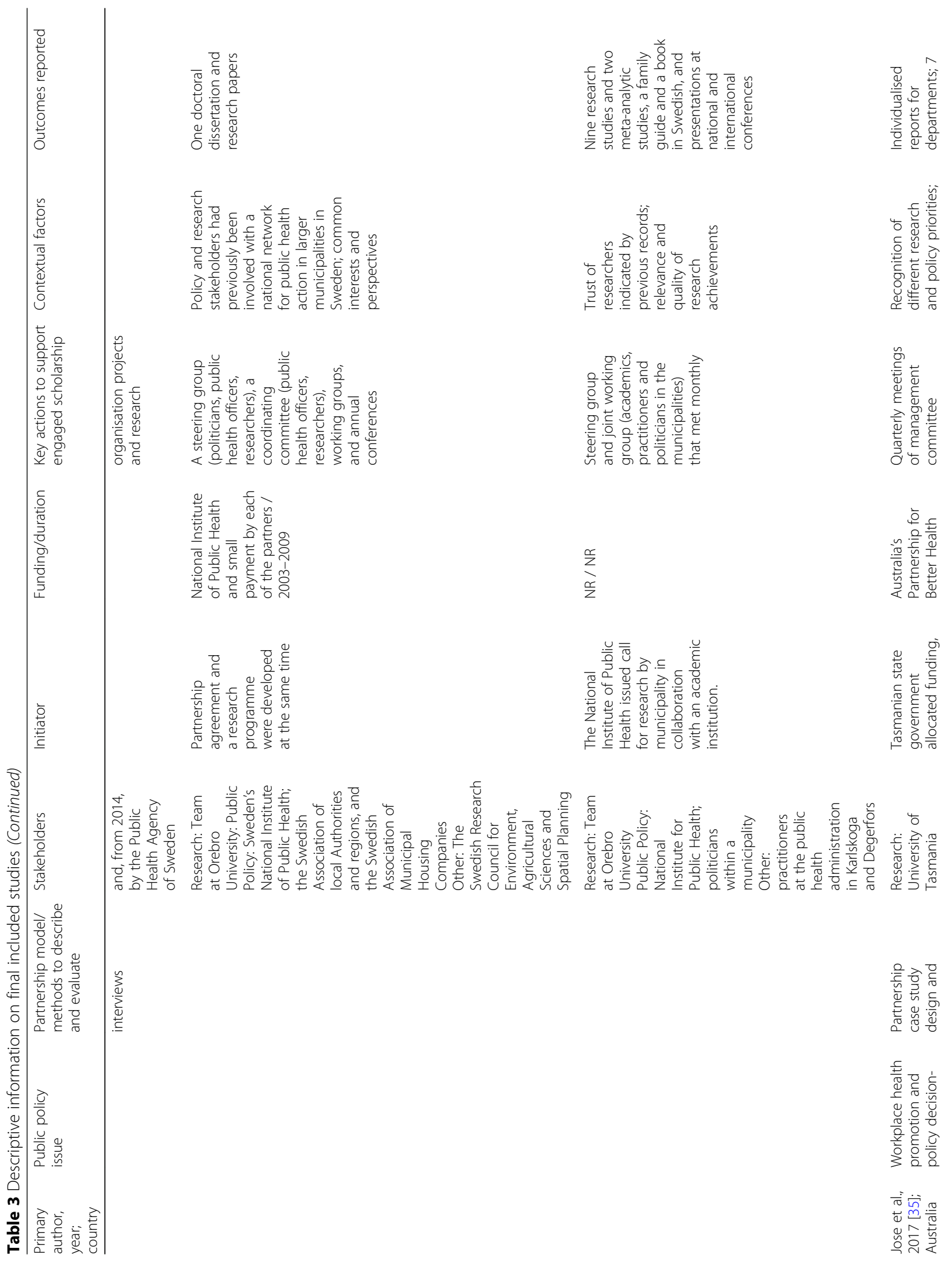




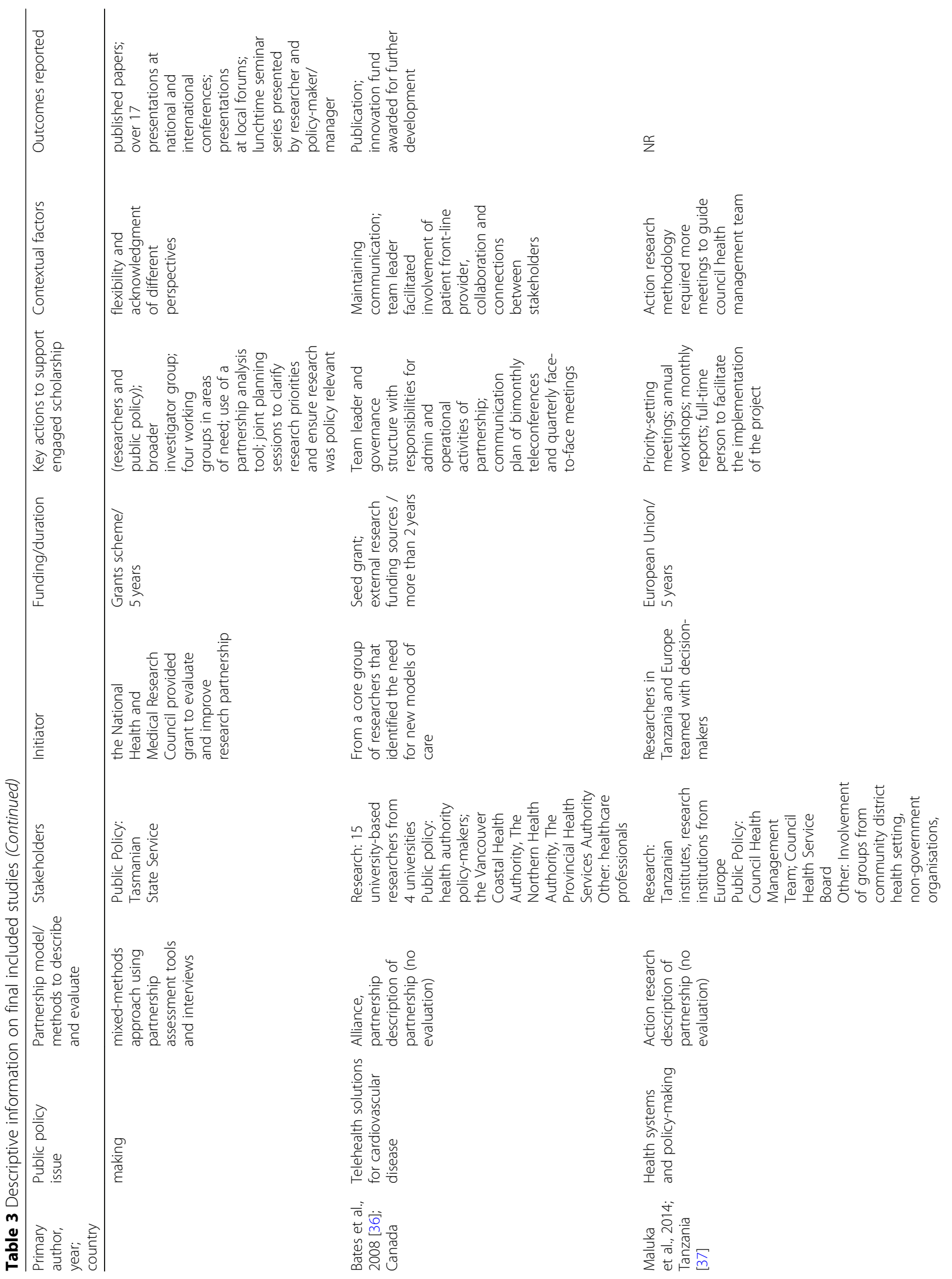




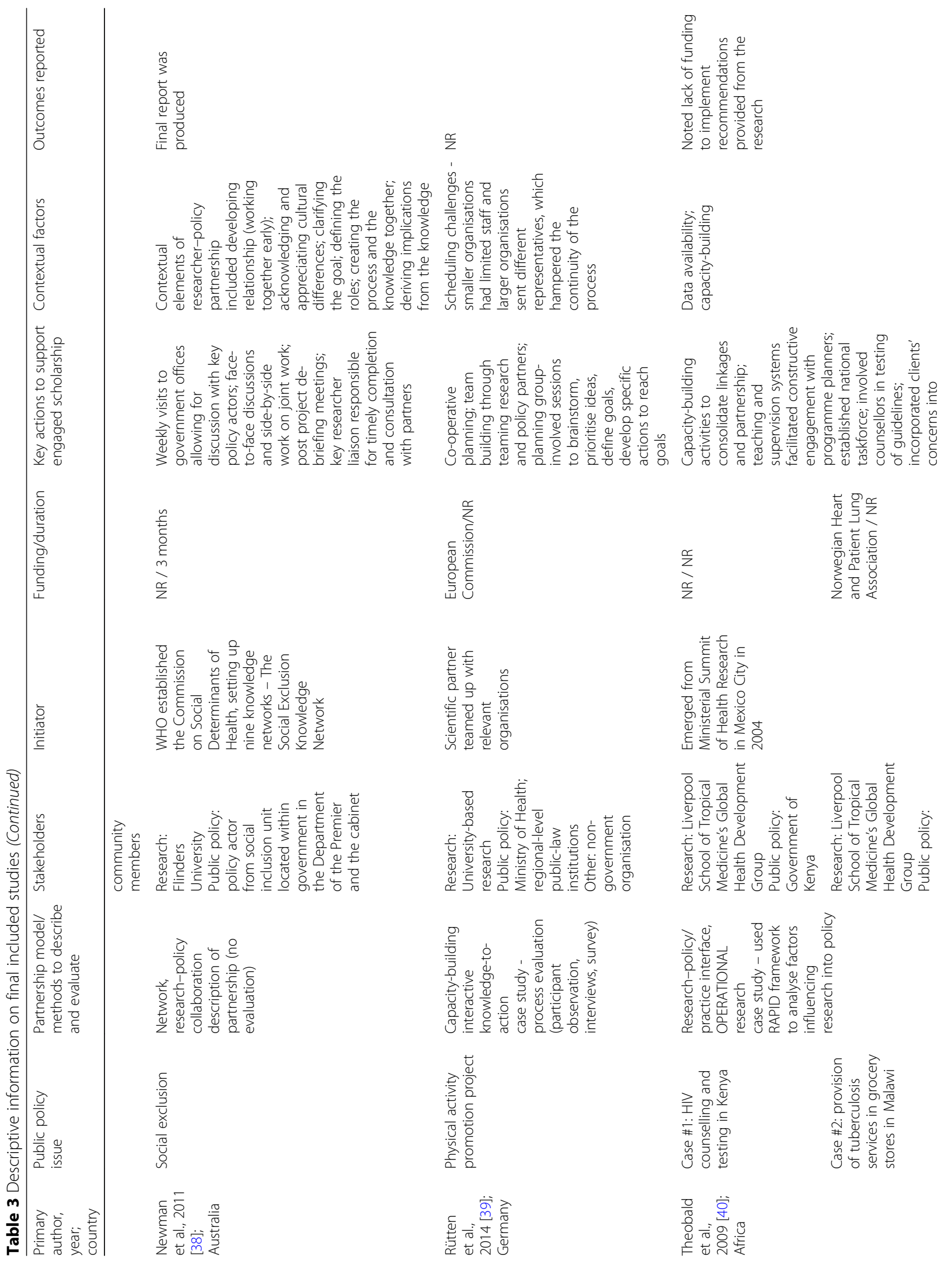




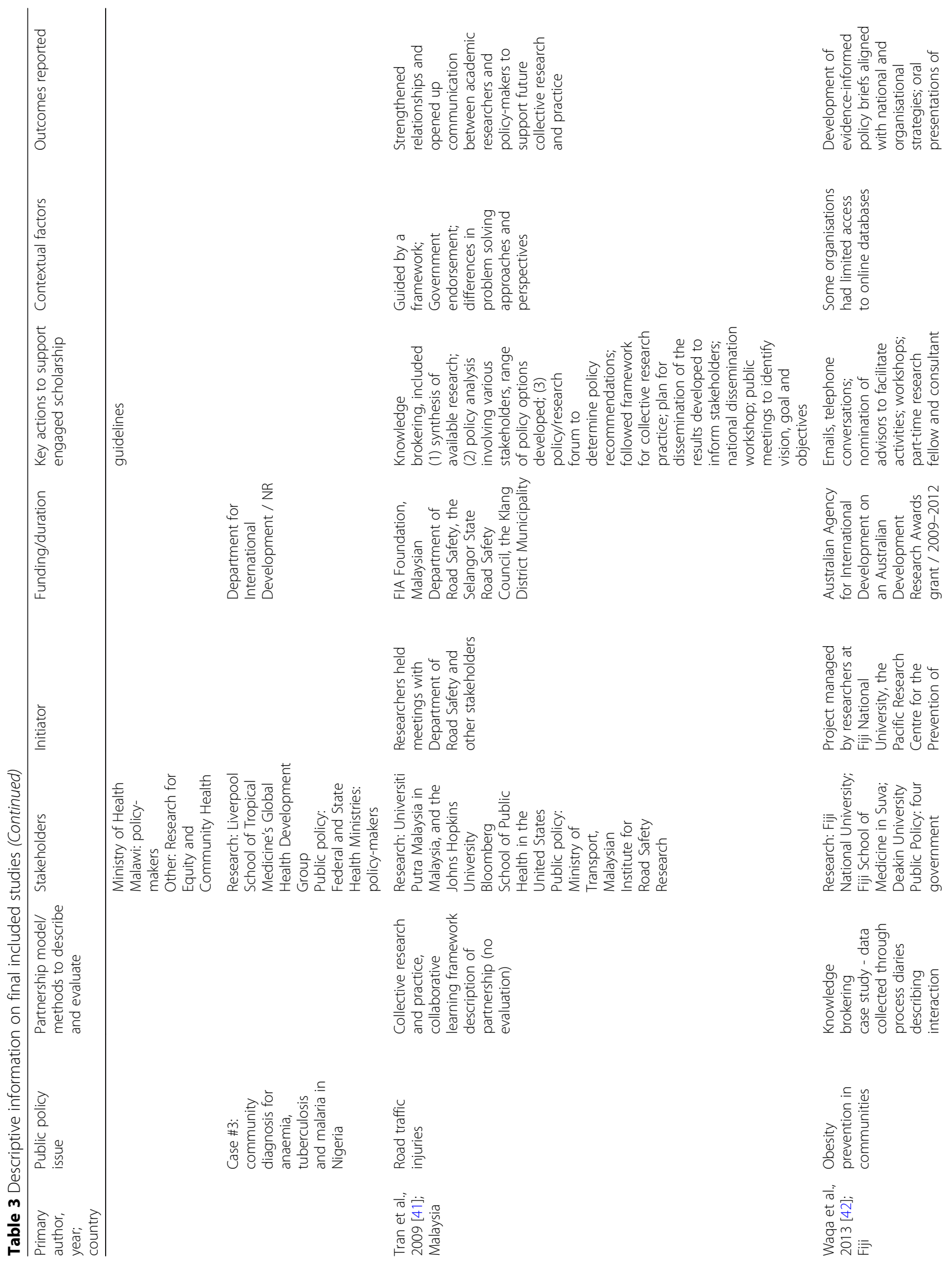




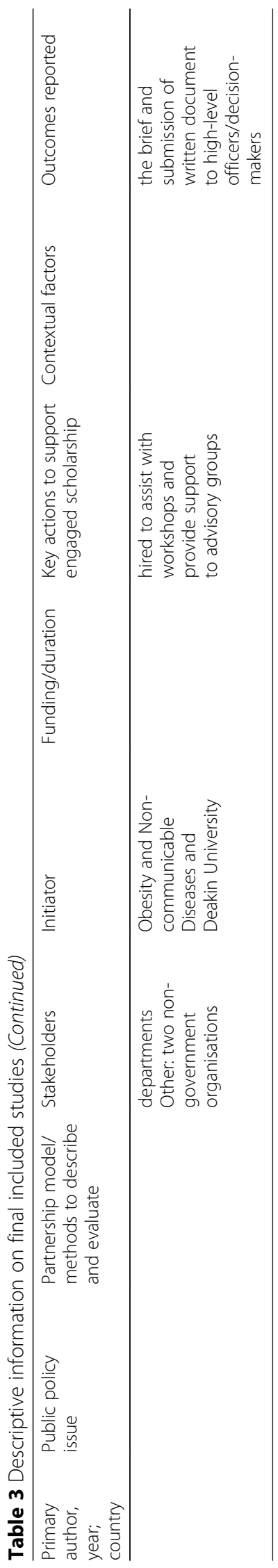


collaboration and integrating diverse perspectives to create more relevant and usable research [1]. Notwithstanding this intent, none of the included studies defined their partnership as ES. However, they all met the inclusion criterion that operationalised ES, namely a partnership where researchers were working with individuals working in public policy toward the same end goal of coproduction and use of knowledge.

Key actions included facilitating frequent interactions with public policy stakeholders and joint planning and execution of data collection and analysis. Critical contextual factors influencing partnerships were clarity in responsibilities, prior relationships or experiences, and respect for partner priorities and perspectives. The application of an ES approach is expected to result in more relevant research through coproduction between researchers and policy actors, thereby increasing the likelihood that the evidence will be used to inform policy decisions. Although the included studies discussed how the results would lead toward public policy decisions, the outcomes reported in the included studies focused on academic outputs, including research papers, dissertations and conference presentations with some additional policy-relevant products such as presentation at local forums, individualised reports or local discussions with stakeholders. None of the included studies specifically articulated how the research led to a policy change; however, this could be due to the nature of timing of the publication and that policy outcomes from ES may take more time to achieve.

The partnership, actions and context were often incomplete and inconsistency was reported. In particular, we were interested in understanding the 'embeddedness' of the researcher in the policy environment. 'Embedded research' is one action that may facilitate ES as it situates a researcher within a policy setting to conduct evaluation and research as a member of the host organisation $[43,44]$. This enables the researcher to be independent from the host organisation but familiar with the policy context, providing an opportunity to engage in critical analysis and bridge knowledge-to-action gaps. For example, Newman et al. [38] described weekly visits to government offices allowing for face-to-face discussion with key policy actors and joint work. The study referred to key elements critical to the success of researcher and public policy partnerships, including developing the relationship and creating the process and knowledge together. These findings reflect the potential importance of greater embeddedness of research within policy, although the other studies in the review did not provide sufficient detail on the context of the partnership to determine the extent to which researchers were embedded in the policy environment. Further, half of the included studies did not use an evaluation method in their study (including Newman et al. [38]), meaning that the actions and context were not systematically collected and may be biased through the accounts of the authors. As a result of these limitations in the literature, it is not possible to determine the relationships between actions, context and outcomes for ES. This is a similar finding by Gagliardi et al. [14] who advocated for more longitudinal approaches to determine the impact of partnerships in research and relationships between approaches and outcomes. The results from this scoping review suggest that further study is needed to more systematically understand the relationships between contexts and actions. It is also recommended that future studies articulate the nature of ES partnerships, including the embeddedness of researchers within policy environments, and use evaluative methods to collect perspectives from the various stakeholders involved to reduce the bias of researcher accounts.

This study is a novel contribution to the literature by focusing on partnerships between researchers and public policy decision-makers on a variety of topics. Previous reviews have explored healthcare research partnerships $[14,45,46]$ and community-based participatory research [8]. The scoping review identified public policy issues across multiple sectors, including early childhood, mental health, health promotion, healthcare, social exclusion and safety. This transdisciplinary approach to the review provides an opportunity to learn about partnership approaches across sectors. An additional 18 studies were excluded due to their structure as a 'research network'. This boundary was necessary to keep the review focused on partnerships that carried out specific project activities with agreed-upon outcomes rather than broad collectives that engage researchers and public policy stakeholders with shared domains of interest but without tangible activities. However, the research network studies were charted in the preliminary stages of the review and similar actions and contexts were reported. These studies also represented multiple sectors, such as health policy, healthy aging and long-term care, public education, regional water issues, wildlife conservation and family violence. One noted difference in the 'research network' studies included further actions related to stakeholder capacity and relationship building, such as workshops and large assemblies. Additional contextual challenges were also mentioned that related to tension and conflicts working within a large research network and balancing the needs of different stakeholders.

\section{Conclusions}

In conclusion, more systematic study of the conditions and actions that influence the coproduction and use of research is needed for a diversity of public policy issues. ES partnerships could be further explored beyond the 
focus on public policy issues to determine the use of this partnership approach within practice-oriented literature. Future research could build on the inherent limitations of the scoping review methodology given their exploratory nature and uncertainty about interpretation due to the lack of quality appraisal [47]. More comprehensive descriptions (including the duration) and evaluations of research partnerships are also needed to elucidate the contextual and process factors that contribute to the research-policy partnerships and to determine the longterm outcomes of its use, given the limited available evidence $[24,48,49]$. This advancement in the literature would help to strengthen research-policy partnerships and their intended outcomes.

\section{Supplementary information}

Supplementary information accompanies this paper at https://doi.org/10. 1186/s12961-020-00613-w.

Additional file 1. Search translation summary.

Additional file 2. PRISMA 2009 flow diagram.

\section{Abbreviations}

ES: Engaged scholarship

\section{Acknowledgements}

The authors would like to thank the following for their important contributions to the manuscript: Cameron Willis for support with design and conception of study; Leah Boulos, Sarah Visintini, Robyn Traynor from the Maritime SPOR (Strategic Patient Oriented Research) Support Unit for support with the search strategy; Kaleigh Chiasson and Brittany Barber for support with study selection and charting.

\section{Authors' contributions}

JDM and BLR conceived and designed the study. JDM conducted the search, article selection, and data extraction with support from experts in knowledge synthesis and research assistants (see below) with ongoing advice from BLR. JDM wrote the manuscript. JDM and BLR interpreted the data and critically revised the manuscript. The authors read and approved the final manuscript.

\section{Funding}

This research was supported by the Canadian Cancer Society (grant \#703878 and \#2011-701019). This research was also undertaken, in part, thanks to funding from the Canada Research Chairs program.

\section{Availability of data and materials}

Not applicable.

\section{Ethics approval and consent to participate}

Not applicable.

\section{Consent for publication}

Not applicable.

\section{Competing interests}

The authors declare that they have no competing interests.

\section{Author details}

${ }^{1}$ Faculty of Education and Department of Child and Youth Study, Mount Saint Vincent University, 166 Bedford Highway, Halifax, Nova Scotia B3M 2J6, Canada. ${ }^{2}$ Healthy Populations Institute, Dalhousie University, Halifax, Nova Scotia B3H 4R2, Canada. ${ }^{3}$ Faculty of Applied Health Sciences and Renison University College, University of Waterloo, 200 University Avenue West, Waterloo, Ontario N2L 3G1, Canada.
Received: 23 September 2019 Accepted: 3 August 2020

Published online: 26 August 2020

\section{References}

1. Van de Ven AH, Johnson PE. Knowledge for theory and practice. Acad Manage Rev. 2006;31(4):802-21.

2. Boyer EL. Scholarship Reconsidered: Priorities of the Professoriate. New York: The Carnegie Foundation for the Advancement of Teaching; 1990. http://1 84.168.109.199:8080/jspui/handle/123456789/2134. Accessed 15 Feb 2016.

3. Kasworm CE, Abdrahim NA. Scholarship of engagement and engaged scholars: through the eyes of exemplars. J High Educ Outreach Engagem. 2014;18(2):121-48

4. Doberneck DM, Glass CR, Schweitzer J. From rhetoric to reality: a typology of publically engaged scholarship. J High Educ Outreach Engagem. 2010; 14(4):5-35.

5. Holland D, Powell DE, Eng E, Drew G. Models of engaged scholarship: an interdisciplinary discussion. Collab Anthropol. 2010;3(1):1-36.

6. Calleson DC, Jordan C, Seifer SD. Community-engaged scholarship: Is faculty work in communities a true academic enterprise? Acad Med. 2005;80(4): 317-21.

7. Flinders $M$. The politics of engaged scholarship: impact, relevance and imagination. Policy Polit. 2013:41(4):621-42.

8. Jagosh J, Macaulay AC, Pluye P, Salsberg J, Bush PL, Henderson J, et al. Uncovering the benefits of participatory research: implications of a realist review for health research and practice. Milbank Q. 2012;90(2):311-46.

9. Bowen SJ, Graham ID. From Knowledge Translation to Engaged Scholarship: Promoting Research Relevance and Utilization. Arch Phys Med Rehabil. 2013;94(1):S3-8.

10. Shaxson $L$, Bielak $A T$, et al. Expanding our understanding of $K^{*}(K T, K E, K T T$, $\mathrm{KMb}, \mathrm{KB}, \mathrm{KM}$, etc.) a concept paper emerging from the $\mathrm{K}^{*}$ conference held in Hamilton, Ontario, Canada. Hamilton: United Nations University, Institute for Water, Environment and Health; 2012.

11. Atkinson J-A, Vallely A, Fitzgerald $L$, Whittaker $M$, Tanner $M$. The architecture and effect of participation: a systematic review of community participation for communicable disease control and elimination. Implications for malaria elimination. Malar J. 2011;10:225.

12. Brett J, Staniszewska S, Mockford C, Herron-Marx S, Hughes J, Tysall C, et al. A systematic review of the impact of patient and public involvement on service users, researchers and communities. Patient. 2014;7(4):387-95.

13. Dwamena F, Holmes-Rovner M, Gaulden CM, Jorgenson S, Sadigh G, Sikorskii A, et al. Interventions for providers to promote a patient-centred approach in clinical consultations. Cochrane Database Syst Rev. 2012;12: CD003267.

14. Gagliardi AR, Berta W, Kothari A, Boyko J, Urquhart R. Integrated knowledge translation (IKT) in health care: a scoping review. Implement Sci. 2016;11:38.

15. George AS, Mehra V, Scott K, Sriram V. Community participation in health systems research: a systematic review assessing the state of research, the nature of interventions involved and the features of engagement with communities. PLoS One. 2015;10(10):e0141091.

16. Orton L, Lloyd-Williams F, Taylor-Robinson D, O'Flaherty M, Capewell S. The use of research evidence in public health decision making processes: systematic review. PLoS One. 2011;6(7):e21704.

17. Wallace J, Byrne C, Clarke M. Making evidence more wanted: a systematic review of facilitators to enhance the uptake of evidence from systematic reviews and meta-analyses. Int J Evid Based Healthc. 2012;10(4):338-46.

18. Hawe P, Potvin L. What is population health intervention research? Can J Public Health. 2009;100(1):18-14.

19. Hobin EP, Hayward S, Riley B, Di Ruggiero E, Birdsell J. Maximising the use of evidence: exploring the intersection between population health intervention research and knowledge translation from a Canadian perspective. Evid Policy. 2012:8(1):97-115.

20. Connell NAD, Klein JH, Powell PL. It's tacit knowledge but not as we know it: redirecting the search for knowledge. J Oper Res Soc. 2003;54(2):140-52.

21. Kothari A, Rudman D, Dobbins M, Rouse M, Sibbald S, Edwards N. The use of tacit and explicit knowledge in public health: a qualitative study. Implement Sci. 2012;7:20.

22. Oliver K, Innvar S, Lorenc T, Woodman J, Thomas J. A systematic review of barriers to and facilitators of the use of evidence by policymakers. BMC Health Serv Res. 2014;14(1):2.

23. Sarkies MN, Bowles K-A, Skinner EH, Haas R, Lane H, Haines TP. The effectiveness of research implementation strategies for promoting 
evidence-informed policy and management decisions in healthcare: a systematic review. Implement Sci. 2017;12:132.

24. Gagliardi AR, Kothari A, Graham ID. Research agenda for integrated knowledge translation (IKT) in healthcare: what we know and do not yet know. J Epidemiol Community Health. 2017;71(2):105-6.

25. Arksey H, O'Malley L. Scoping studies: towards a methodological framework. Int J Soc Res Methodol. 2005;8:19-32

26. Levac D, Colquhoun H, O'Brien KK. Scoping studies: advancing the methodology. Implement Sci. 2010;5(1):69.

27. Pawson R, Greenhalgh T, Harvey G, Walshe K. Realist review--a new method of systematic review designed for complex policy interventions. J Health Serv Res Policy. 2005;10(Suppl 1):21-34.

28. Lacouture A, Breton E, Guichard A, Ridde V. The concept of mechanism from a realist approach: a scoping review to facilitate its operationalization in public health program evaluation. Implement Sci. 2015;10:153.

29. Denyer D, Tranfield D. Producing a systematic review. In: Buchanan D, Bryman A, editors. The SAGE handbook of organizational research methods. London: Sage Publications; 2009. p. 671-89.

30. Kraft ME, Furlong SR. Public Policy: Politics, Analysis, and Alternatives. Singapore: CQ Press, Imprint of SAGE Publications, Inc; 2018.

31. Braun V, Clarke V. Using thematic analysis in psychology. Qual Res Psychol. 2006;3(2):77-101.

32. Bowes JM, Harrison L, Ungerer J, Simpson T, Wise S, Sanson A, et al. Child care choices: a longitudinal study of children, families and child care in partnership with policy makers. Aust Educ Res. 2004:31(3):69-86.

33. Bumbarger BK, Campbell EM. A state agency-university partnership for translational research and the dissemination of evidence-based prevention and intervention. Adm Policy Ment Health. 2012;39(4):268-77.

34. Eriksson CC-G, Fredriksson I, Fröding K, Geidne S, Pettersson C. Academic practice-policy partnerships for health promotion research: experiences from three research programs. Scand J Public Health. 2014;42(15 Suppl):8895.

35. Jose K, Venn A, Jarman L, Seal J, Teale B, Scott J, et al. Partnering Healthy@Work: an Australian university-government partnership facilitating policy-relevant research. Health Promot Int. 2017;32(6):964-76.

36. Bates J, Lavoie JG, Policy, Lear SA, Research SJ and RES on behalf of the BCA on T. The British Columbia Alliance on Telehealth Research and Policy. Healthcare Quarterly. 2008. http://www.longwoods.com/content/20092. Accessed 29 Mar 2018

37. Maluka S, Kamuzora P, Ndawi B, Hurtig A-K. Involving decision-makers in the research process: Challenges of implementing the accountability for reasonableness approach to priority setting at the district level in Tanzania. Glob Public Health. 2014;9(7):760-72.

38. Newman L, Biedrzycki K, Patterson J, Baum F. Partnership in knowledge creation: lessons learned from a researcher-policy actor partnership to coproduce a rapid appraisal case study of South Australia's Social Inclusion Initiative. Evid Policy. 2011;7(1):77-96.

39. Rütten A, Gelius P. Building policy capacities: an interactive approach for linking knowledge to action in health promotion. Health Promot Int. 2014; 29(3):569-82.

40. Theobald S, Taegtmeyer M, Squire SB, Crichton J, Simwaka BN, Thomson R, et al. Towards building equitable health systems in sub-Saharan Africa: lessons from case studies on operational research. Health Res Policy Syst. 2009;7:1.

41. Tran NT, Hyder AA, Kulanthayan S, Singh S, Umar RSR. Engaging policy makers in road safety research in Malaysia: a theoretical and contextual analysis. Health Policy. 2009;90(1):58-65.

42. Waqa G, Mavoa H, Snowdon W, Moodie M, Schultz J, McCabe M, et al. Knowledge brokering between researchers and policymakers in Fiji to develop policies to reduce obesity: a process evaluation. Implement Sci. 2013;8:74

43. McGinity R, Salokangas M. Introduction: 'embedded research' as an approach into academia for emerging researchers. Manag Educ. 2014;28(1): 3-5.

44. Lewis S, Russell A. Being embedded: a way forward for ethnographic research. Ethnography. 2011;12(3):398-416.

45. Guise J-M, O'Haire C, McPheeters M, Most C, Labrant L, Lee K, et al. A practice-based tool for engaging stakeholders in future research: a synthesis of current practices. J Clin Epidemiol. 2013;66(6):666-74.
46. Lawrence LM, Bishop A, Curran J. Integrated knowledge translation with public health policy makers: a scoping review. Healthc Policy Polit Sante. 2019;14(3):55-77.

47. O'Brien KK, Colquhoun H, Levac D, Baxter L, Tricco AC, Straus S, et al. Advancing scoping study methodology: a web-based survey and consultation of perceptions on terminology, definition and methodological steps. BMC Health Serv Res. 2016;16:305.

48. Fransman J. Charting a course to an emerging field of "research engagement studies": a conceptual meta-synthesis. Res All. 2018;2(2):185229.

49. Oliver K, Kothari A, Mays N. The dark side of coproduction: do the costs outweigh the benefits for health research? Health Res Policy Syst. 2019;17: 33.

\section{Publisher's Note}

Springer Nature remains neutral with regard to jurisdictional claims in published maps and institutional affiliations.
Ready to submit your research? Choose BMC and benefit from:

- fast, convenient online submission

- thorough peer review by experienced researchers in your field

- rapid publication on acceptance

- support for research data, including large and complex data types

- gold Open Access which fosters wider collaboration and increased citations

- maximum visibility for your research: over $100 \mathrm{M}$ website views per year

At BMC, research is always in progress.

Learn more biomedcentral.com/submissions 